\title{
1 Species packing and the latitudinal gradient in local beta-diversity
}

$2 \mathrm{Ke} \mathrm{Cao}^{1,2}$, Richard Condit ${ }^{3,4}$, Xiangcheng $\mathrm{Mi}^{1^{*}}$, Lei Chen ${ }^{1}$, Haibao Ren ${ }^{1}$, Wubing $\mathrm{Xu}^{1}$, David

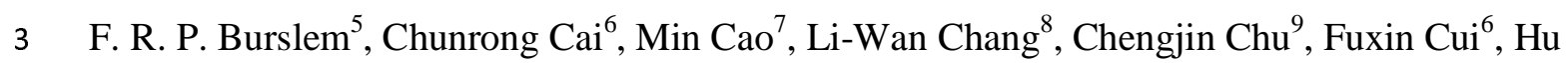

$4 \mathrm{Du}^{10}$, Sisira Ediriweera ${ }^{11}$, C.S.V. Gunatilleke ${ }^{12}$, I.U.A.N. Gunatilleke ${ }^{12}$, Zhanqing Hao $^{13}$,

5 Guangze $\mathrm{Jin}^{14}, \mathrm{Jinbo}^{6}{ }^{6}$, Buhang $\mathrm{Li}^{9}$, Yide $\mathrm{Li}^{15}$, Yankun Liu ${ }^{16}$, Hongwei $\mathrm{Ni}^{6}$, Michael J.

6 O'Brien $^{17}$, Xiujuan Qiao ${ }^{18}$, Guochun Shen ${ }^{19}$, Songyan Tian $^{16}$, Xihua Wang ${ }^{19}$, Han Xu ${ }^{15}$,

7 Yaozhan $\mathrm{Xu}^{18}$, Libing Yang ${ }^{6}$, Sandra L. Yap ${ }^{20}$, Juyu Lian $^{21}$, Wanhui Ye ${ }^{21}$, Mingjian Yu ${ }^{22}$,

8 Sheng-Hsin $\mathrm{Su}^{8}$, Chia-Hao Chang-Yang ${ }^{23}$, Yili Guo ${ }^{24}$, Xiankun $\mathrm{Li}^{24}$, Fuping Zeng ${ }^{10}$,

9 Daoguang Zhu ${ }^{6}$, Li Zhu ${ }^{1}$, I-Fang Sun ${ }^{25}$, Keping Ma ${ }^{*}$, Jens-Christian Svenning ${ }^{26}$

$11{ }^{1}$ State Key Laboratory of Vegetation and Environmental Change, Institute of Botany, Chinese

12 Academy of Sciences, Beijing 100093

${ }^{2}$ Key Laboratory of Biodiversity Sciences and Ecological Engineering, Ministry of Education,

College of Life Sciences, Beijing Normal University, Beijing 100875

${ }^{3}$ Morton Arboretum, 4100 Illinois Rte. 53, Lisle, IL 60532, USA

${ }^{4}$ Field Museum of Natural History, 1400 S. Lake Shore Dr., Chicago, IL 60605, USA

$17{ }^{5}$ School of Biological Sciences, University of Aberdeen, Cruickshank Building, St Machar

Drive, Aberdeen AB24 3UU, UK

${ }^{6}$ Institue of Natural Resources and Ecology, Heilongjiang Academy of Sciences, Harbin

7CAS Key Laboratory of Tropical Forest Ecology, Xishuangbanna Tropical Botanical Garden,

Chinese Academy of Sciences, Kunming 650223

${ }^{8}$ Taiwan Forestry Research Institute, 53 Nanhai Road, Taipei 10066

${ }^{9}$ Sun Yat-sen University, Guangzhou 510275 
$25{ }^{10}$ Institute of Subtropical Agriculture, Chinese Academy of Sciences, Changsha, Hunan

$26 \quad 410125$

$27{ }^{11}$ Faculty of Applied Sciences, Uva Wellassa University, Badulla 90000, Sri Lanka

$28{ }^{12}$ Department of Botany, University of Peradeniya, Peradeniya 20400, Sri Lanka

$29 \quad{ }^{13}$ Institute of Applied Ecology, Chinese Academy of Sciences, Shenyang 110016

$30 \quad{ }^{14}$ Center for Ecological Research, Northeast Forestry University, Harbin 150040

$31{ }^{15}$ Research Institute of Tropical Forestry, Chinese Academy of Forestry, Guangzhou 510520

$32{ }^{16}$ Heilongjiang Forest Engineering and Environment Institute, Harbin 150040

$33{ }^{17}$ Área de Biodiversidad y Conservación, Universidad Rey Juan Carlos, c/ Tulipán s/n., E-

3428933 Móstoles, Spain

$35{ }^{18}$ Key Laboratory of Aquatic Botany and Watershed Ecology, Wuhan Botanical Garden,

36 Chinese Academy of Sciences, 430074

$37{ }^{19}$ East China Normal University, Shanghai 200241

$38{ }^{20}$ Institute of Biology, University of the Philippines, Diliman, Quezon City, PH 1101,

$39 \quad$ Philippines

$40 \quad{ }^{21}$ South China Botanical Garden, Chinese Academy of Sciences, Guangzhou 510650

$41 \quad{ }^{22}$ College of Life Sciences, Zhejiang University, Hangzhou 310058

$42 \quad{ }^{23}$ National Sun Yat-sen University, Kaohsiung, 80424

$43{ }^{24}$ Guangxi Institute of Botany, Guangxi Zhuang Autonomous Region and Chinese Academy

44 of Sciences, Guilin 541006

$45{ }^{25}$ Department of Natural Resources and Environmental Studies, National Dong Hwa

46 University, Hualian 97401

$47{ }^{26}$ Center for Biodiversity Dynamics in a Changing World (BIOCHANGE) \& Section for

48 Ecoinformatics and Biodiversity, Department of Biology, Aarhus University, Ny Munkegade

49 114, DK-8000 Aarhus C, Denmark 
50 *Correspondence author: Xiangcheng Mi, Keping Ma

51 Email: mixiangcheng@ibcas.ac.cn, kpma@ibcas.ac.cn

52 Address: State Key Laboratory of Vegetation and Environmental Change, Institute of Botany,

53 Chinese Academy of Sciences, Beijing 100093;

\section{Abstract}

The latitudinal gradient of declining species richness at higher latitudes is among the most fundamental patterns in ecology. However, whether changes in species composition across space (beta-diversity) contribute to this global gradient of species richness remains debated. Previous studies that failed to resolve the issue suffered from a well-known tendency for small samples in high gamma-diversity areas to inflate measures of beta-diversity. We provide here a rigorous test, comparing species-packing and local heterogeneity across a latitudinal gradient in tree species richness in Asia, using beta-diversity metrics that correct the gamma-diversity and sampling bias. Our data include 21 large forest plots across a wide environmental gradient in East Asia. We demonstrate that local beta-diversity increases with topographic heterogeneity, but after accounting for this and correcting the gamma-diversity bias, tropical forests still have higher beta-diversity than temperate, contributing to the latitudinal gradient of species richness. This supports the hypothesis of tighter species packing and larger niche space in tropical forests while demonstrating the importance of local processes in controlling beta-diversity.

\section{Main Text}

Beta-diversity is the spatial organization of local (alpha-) diversity at larger scales, and it is arguably more important to conservation than local diversity ${ }^{1-3}$. Conserving species richness, for example, must consider whether diversity is concentrated within sites or spread across 
many sites ${ }^{1}$. Are observed gradients in species richness around the world caused by

differences in beta-diversity ${ }^{4-7}$ ? For example, is the well-known latitudinal gradient in species richness associated with beta-diversity, in other words, do tropical communities have more habitat heterogeneity, larger niche space or narrower niches than temperate communities?

These questions continue to be debated, with researchers reaching opposite conclusions ${ }^{8-13}$. Underlying the debate has been controversy about statistical biases in tools for measuring beta-diversity ${ }^{12,14-16}$.

The bias arising in beta-diversity metrics is a dependence on sample size that interacts with overall species richness (gamma-diversity) ${ }^{12,14-16}$. It is easy to illustrate using simple measures of species overlap. Small samples never capture all local species, and it follows that two small samples will appear to differ by randomly capturing a different set of local species, causing an increase in species overlap with the fraction of species sampled ${ }^{14,16}$. As a result, high local species richness will artificially inflate beta-diversity ${ }^{12}$. This bias has led to metrics that correct for sample size ${ }^{14,17,18}$ or tools based on comparisons with null models ${ }^{12,15}$.

Crucial in the sample size bias is the dependence on gamma-diversity it engenders, since bigger samples are needed in richer communities ${ }^{14,16,17}$. Once correcting for sample size bias, gamma-diversity dependence should be removed, and it should be straightforward to compare beta-diversity across a gradient of species diversity in order to judge the importance of local species packing.

We carry out this comparison using the steep latitudinal gradient in tree species richness as documented in our census of 3 million trees at 21 sites spanning $50^{\circ}$ of latitude in East Asia

(Fig. 1 and Extended Data Table 1) ${ }^{19,20}$. In a simulation study ${ }^{18}$, we tested several metrics of beta-diversity, including a null model approach plus sample size correction methods designed by Chao et al. ${ }^{17}$. We identified the corrected beta Shannon entropy and similar metrics as highly effective at removing dependence on gamma-diversity and sample size ${ }^{18}$. These 
indices thus allow us to answer two fundamental questions about the source of local species richness: 1) Is there a latitudinal gradient in beta-diversity revealed by the corrected beta Shannon entropy? 2) Do local environmental heterogeneity, niche specialization (the ratio of the narrowness of available habitat of a plot to that of a species) and marginality (the distance between the species optimum relative to the mean habitat of a plot) contribute to the latitudinal patterns of local beta-diversity? By testing simultaneously the importance of local heterogeneity and latitude we can establish whether species-packing contributes to higher richness in tropical relative to temperate forests ${ }^{21,22}$.

Gamma-diversity declined by more than forty-fold between tropical and temperate latitudes, from 818 species at Pasoh to 18 at Daxinganling (Extended Data Table 1). Local betadiversity also declined with latitude, and this pattern was stronger at small scales (Fig. 2a). We found positive correlations between local topographic heterogeneity and beta-diversity (Fig. 2b). Further, beta-diversity was correlated with both latitude and topographic heterogeneity in multiple linear regression models, but the relative effect size varied as scale changed (Fig. 2c). Specifically, the effect of adjusted latitude decreased, whereas the effect of topographic heterogeneity increased at larger scales.

Both community-level niche specialization (species-level niche specialization weighted by relative species abundance) and niche marginality (species-level niche marginality weighted by relative species abundance) decreased from tropical to temperate forests after controlling local topographic heterogeneity, suggesting narrower niche width and larger niche space in tropical forests (Figs. 3a-3d). Moreover, niche specialization and niche marginality were positively correlated with each other across scales (Extended Data Figs. 2g-2i). Meanwhile, they were both well predicted by local topographic heterogeneity across scales (Extended Data Figs. 2a-2f). Furthermore, multiple linear regression models revealed that the effect sizes 
of topographic heterogeneity were much larger than those of adjusted latitude across scales,

126

127

128

although their effect sizes were scale-dependent (Figs. 3b and 3d).

Our results confirm that local beta-diversity increases from boreal toward tropical forests of Asia after accounting for local topographic heterogeneity. Previous studies demonstrating this pattern ${ }^{3,5,21}$ have been questioned due to the bias of inflated beta-diversity at high gammadiversity regions ${ }^{12,15}$. We found that the gradient persisted, however, even after removing the gamma-diversity bias and controlling for local topographic heterogeneity. This suggests that local beta-diversity contributes to the latitudinal gradient in species richness.

Given higher species turnover with topography and greater niche specialization and marginality at the same scales at lower latitude, there must be tighter species packing and larger niche space in tropical relative to temperate forests ${ }^{4,7,21,23,24}$. This hypothesis has been floated for decades, attributed to higher and more stable productivity in the tropics: a larger niche space enables more species to persist at low abundance and allows species to specialize on narrower subsets of the resources available ${ }^{7,22-25}$. Since topographic heterogeneity did not vary with latitude (Extended Data Fig. 3), it appears that local topographic heterogeneity does not contribute to the latitudinal gradient in local beta-diversity, in line with previous findings of Ricklefs and $\mathrm{He}^{26}$ and Chu et al. ${ }^{27}$.

We also conclude that local beta-diversity is driven largely by local processes-specifically, topographic heterogeneity and the niche differentiation it fosters (Figs. 2 and 3). This may seem an unsurprising result, but the role of local ecological processes has been questioned given the broad latitudinal gradient of gamma-diversity ${ }^{4,12}$. We suggest that the effect of local processes has been obscured by gamma-diversity dependence in previous studies ${ }^{15}$. Moreover, our large samples over 55 degrees of latitude provide comparable measures of niche differentiation, topographic heterogeneity, and beta-diversity, well beyond what was 
150

151

152

153

154

155

156

157

available in early studies ${ }^{28,29}$. Our results could be refined by considering the influence of additional factors that contribute to local environmental heterogeneity and niche differentiation, such as soil types and soil nutrients ${ }^{30}$, because we expect these additional local factors to contribute to beta-diversity. In addition, it is necessary to examine these metrics of beta-diversity that incorporate gamma-diversity and sample size corrections in other taxa and regions. Gamma-diversity dependence is also associated with other attributes of ecosystem such as species abundance distribution ${ }^{31}$ and should be examined in other systems.

We found that a latitudinal gradient in local beta-diversity contributes to the broad latitudinal pattern of species richness after separately controlling for gamma-diversity and local topographic heterogeneity. The results suggest tighter species packing and larger niche space in tropical forests ${ }^{4,22,23}$, but also confirmed environmental heterogeneity as a determinant of beta-diversity. Our findings may help resolve recent debates on the contribution of local betadiversity to latitudinal gradient of species richness.

\section{Materials and Methods}

Forest dynamic plots We used data from 21 forest dynamics plots that are part of the ForestGEO and Chinese Forest Biodiversity Monitoring Networks ${ }^{19,20}$ (Fig. 1a and Extended Data Table 1). All stems with diameter at breast height $(\mathrm{DBH}) \geq 1 \mathrm{~cm}$ were spatially mapped, tagged, measured and identified to species ${ }^{32}$. The plots range from tropical rain forest at $2.98^{\circ}$ $\mathrm{N}$ latitude to boreal forest at $51.82^{\circ} \mathrm{N}$ latitude (Extended Data Table 1). Plots vary from sea level to more than $1400 \mathrm{~m}$ elevation, and within-plot elevation range is as low as $17.7 \mathrm{~m}$ and as high as $298.6 \mathrm{~m}$ (Extended Data Table 1 and Fig. 1b). 
174 Measurement of beta-diversity To circumvent gamma-diversity dependence caused by sample-size bias of beta-diversity metrics, we used a correction method designed for beta Shannon entropy based on the relationship between cumulative diversity curve and sample size $^{33}$. The beta Shannon entropy measures the heterogeneity of pooled communities, and is calculated as the effective number of compositionally distinct and equally abundant communities ${ }^{34,35}$. As the beta Shannon entropy incorporates species abundance, it could weight common or rare species more by changing the diversity order $q^{34}$. Here we chose diversity of order $q=1$ for weighting all species by their abundance, without favoring either common or rare species. Additionally, observed species diversity in a sample is known to be a biased estimate of true species diversity, and is highly sensitive to the area surveyed, the number of individuals counted, and the regional species pool size ${ }^{36}$. We thus used a samplesize dependence correction method to produce accurate, low-bias estimates of the beta Shannon entropy for comparing beta-diversity among regions ${ }^{17,33}$. In this approach, similar to a species accumulation curve, the expected cumulative alpha- or gamma-diversity is analytically depicted as a function of sample size, while sample completeness is estimated from community structures of samples ${ }^{17,33}$. Beta-diversity can then be estimated from the predicted alpha- and gamma-diversity under hypothetical complete sampling based on the diversity-sample size curve. For a comparison, we also used a pairwise dissimilarity metric the Jaccard-Chao index (Extended Data Fig. 1), which corrects undersampling bias by estimating the effect of undetected shared species ${ }^{37}$. Our simulations confirmed that $\beta$ metrics that incorporate an undersampling correction method are more effective at removing dependence on gamma-diversity and sample size, compared with other conventional betadiversity metrics ${ }^{18}$.

\section{Local topographic heterogeneity, community-level niche differentiation Local}

topographic heterogeneity was quantified by the surface to planimetric area ratio ${ }^{28}$. Niche 
differentiation was described using attributes of specialization and marginality. Niche specialization was defined as the ratio of the standard deviation of available habitat for a community to that used by a species, and marginality was defined as the ecological distance between a species optimum and the mean habitat within the plot ${ }^{38,39}$. Specialization and marginality were calculated for each species with species composition data and six topographic factors: mean elevation, convexity, slope, aspect, topographical wetness index (TWI) and altitude above channel (ACH) - across spatial scales ${ }^{40-42}$. Aspect was computed as $\sin ($ aspect) and $\cos ($ aspect), and other topographic variables were Box-Cox transformed before being included into analysis ${ }^{43}$. We then calculated the mean community-level niche specialization and marginality across all species occurring in at least ten subplots, weighting by species abundance.

Statistical analysis To examine the significance of latitudinal gradients in explaining local beta-diversity, niche specialization and niche marginality, we first modeled beta-diversity, community-level niche specialization and niche marginality against topographic heterogeneity and adjusted latitude (an upward shift of $100 \mathrm{~m}$ approximately equals to a poleward shift of $100 \mathrm{~km}$ ) separately using simple linear regression models. Subsequently, to determine the relative effect sizes of adjusted latitude and topography, we performed multiple linear regression models with beta-diversity, niche specialization and marginality as response variables respectively, and all variables were standardized by $\left(x-x^{\prime}\right) / S D(x)$ before being included. To achieve normality of niche specialization (Extended Data Fig. 4a), the log- and Box-Cox transformation ${ }^{43}$ were employed (Extended Data Figs. $4 \mathrm{~b}$ and $4 \mathrm{c}$ ). Finally, the BoxCox transformed niche specialization were used in analyses, and for comparison, it was minmax normalized into the range between $[0,1]$ using $((x-\min (x)) /(\max (x)-\min (x))$. In total, we conducted all the analyses across three spatial scales by dividing plots into quadrats of different grain sizes $(10 \mathrm{~m} \times 10 \mathrm{~m}, 20 \mathrm{~m} \times 20 \mathrm{~m}$ and $50 \mathrm{~m} \times 50 \mathrm{~m})$. 
224 All statistical analyses were performed with $\mathrm{R}$ software, version $3.6 .4^{44}$. The corrected

225 Shannon entropy index was calculated using $\mathrm{R}$ package 'entropart' ${ }^{45}$. The topographic

226 variables were computed using 'RSAGA' package ${ }^{46}$ and SAGA GIS ${ }^{47}$. Ecological niche

227 factor analysis (ENFA) was implemented to calculate niche metrics using $\mathrm{R}$ package

228 'adehabitatHS' 48 .

\section{Data availability}

230 The data supporting Figure 1-3 have been deposited in the Dryad Digital Repository

231 (https://datadryad.org/stash/share/6bhhuxg5b3637cgOSzPVQzdyAPh9vy5hf29DCglp6hs).

232 Full census data are available upon reasonable request from the ForestGEO data portal,

233 http://ctfs.si.edu/datarequest/.

\section{Code availability}

235

\section{References:}

1. Socolar, J. B., Gilroy, J. J., Kunin, W. E. \& Edwards, D. P. How Should BetaDiversity Inform Biodiversity Conservation? Trends Ecol Evol 31, 67-80, (2016).

2. Anderson, M. J. et al. Navigating the multiple meanings of beta diversity: a roadmap for the practicing ecologist. Ecol. Lett. 14, 19-28, (2011).

3. Koleff, P., Lennon, J. J. \& Gaston, K. J. Are there latitudinal gradients in species turnover? Global Ecol. Biogeogr. 12, 483-498, (2003).

4. Gaston, K. J. Global patterns in biodiversity. Nature 405, 220-227, (2000).

5. Willig, M. R., Kaufman, D. M. \& Stevens, R. D. Latitudinal gradients of biodiversity: pattern, process, scale, and synthesis. Annu. Rev. Ecol. Evol. Syst., 273-309, (2003). 
249 6. Hillebrand, H. On the generality of the latitudinal diversity gradient. Am Nat 163, 192-

$250 \quad 211,(2004)$.

251 7. Pontarp, M. et al. The Latitudinal Diversity Gradient: Novel Understanding through

252 Mechanistic Eco-evolutionary Models. Trends Ecol. Evol. 34, 211-223, (2019).

253 8. Lenoir, J. et al. Cross-scale analysis of the region effect on vascular plant species 254 diversity in southern and northern European mountain ranges. PLoS One 5, e15734, $255 \quad$ (2010).

256 9. Mori, A. S. et al. Community assembly processes shape an altitudinal gradient of forest biodiversity. Global Ecol. Biogeogr. 22, 878-888, (2013).

10. Qian, H., Chen, S., Mao, L. \& Ouyang, Z. Drivers of $\beta$-diversity along latitudinal gradients revisited. Global Ecol. Biogeogr. 22, 659-670, (2013).

11. Myers, J. A. et al. Beta-diversity in temperate and tropical forests reflects dissimilar mechanisms of community assembly. Ecol. Lett. 16, 151-157, (2013).

12. Kraft, N. J. et al. Disentangling the drivers of beta diversity along latitudinal and elevational gradients. Science 333, 1755-1758, (2011).

13. De Cáceres, M. et al. The variation of tree beta diversity across a global network of forest plots. Global Ecol. Biogeogr. 21, 1191-1202, (2012).

14. Condit, R., Perez, R., Lao, S., Aguilar, S. \& Somoza, A. Geographic ranges and bdiversity: discovering how many tree species there are where. Biologiske Skrifter 55, 57-71, (2005).

15. Myers, J. A. \& LaManna, J. A. The promise and pitfalls of $\beta$-diversity in ecology and conservation. J. Veg. Sci. 27, 1081-1083, (2016).

16. Tuomisto, H. \& Ruokolainen, K. Comment on "Disentangling the drivers of beta diversity along latitudinal and elevational gradients". Science 335, 1573; author reply 1573, (2012). 
274 17. Chao, A. et al. Rarefaction and extrapolation with Hill numbers: a framework for sampling and estimation in species diversity studies. Ecol. Monogr. 84, 45-67, (2014).

18. Cao, K. et al. Comparing the effectiveness of abundance-based $\beta$-diversity metrics in correcting $\gamma$-diversity dependence. Global Ecol. Biogeogr., Under review, (2020).

19. Anderson-Teixeira, K. J. et al. CTFS-ForestGEO: a worldwide network monitoring forests in an era of global change. Glob Chang Biol 21, 528-549, (2015).

20. Feng, G. et al. CForBio: a network monitoring Chinese forest biodiversity. Sci. Bull. 61, 1163-1170, (2016).

21. Vazquez, D. P. \& Stevens, R. D. The latitudinal gradient in niche breadth: concepts and evidence. Am Nat 164, E1-19, (2004).

22. MacArthur, R. H. Patterns of Species Diversity. Biol. Rev. 40, 510-533, (1965).

23. Ricklefs, R. \& Schluter, D. in Species diversity in ecological communities: historical and geographical perspectives (eds RE Ricklefs \& D Schluter) 350-359 (University of Chicago Press, 1993).

24. Brown, J. H. Why are there so many species in the tropics? J. Biogeogr. 41, 8-22, (2014).

25. Evans, K. L., Warren, P. H. \& Gaston, K. J. Species-energy relationships at the macroecological scale: a review of the mechanisms. Biol. Rev. 80, 1-25, (2005).

26. Ricklefs, R. E. \& He, F. Region effects influence local tree species diversity. Proceedings of the National Academy of Sciences 113, 674-679, (2016).

27. Chu, C. et al. Direct and indirect effects of climate on richness drive the latitudinal diversity gradient in forest trees. Ecol. Lett. 22, 245-255, (2019).

28. Brown, C. et al. Multispecies coexistence of trees in tropical forests: spatial signals of topographic niche differentiation increase with environmental heterogeneity. Proc Biol Sci 280, 20130502, (2013). 
29. Shen, G. et al. Quantifying effects of habitat heterogeneity and other clustering processes on spatial distributions of tree species. Ecology 94, 2436-2443, (2013).

30. Baldeck, C. A. et al. Soil resources and topography shape local tree community structure in tropical forests. 280, 20122532, (2013).

31. Chao, A. \& Jost, L. Coverage-based rarefaction and extrapolation: standardizing samples by completeness rather than size. Ecology 93, 2533-2547, (2012).

32. Condit, R. Tropical forest census plots: Methods and results from Barro Colorado Island, Panama and comparison with other plots. (Springer, 1998).

33. Chao, A., Wang, Y. T., Jost, L. \& Warton, D. Entropy and the species accumulation curve: a novel entropy estimator via discovery rates of new species. Methods Ecol. Evol. 4, 1091-1100, (2013).

34. Jost, L. Partitioning diversity into independent alpha and beta components. Ecology 88, 2427-2439, (2007).

35. Tuomisto, H. A diversity of beta diversities: straightening up a concept gone awry. Part 1. Defining beta diversity as a function of alpha and gamma diversity. Ecography 33, 2-22, (2010).

36. Gotelli, N. J. \& Colwell, R. K. Quantifying biodiversity: procedures and pitfalls in the measurement and comparison of species richness. Ecol. Lett. 4, 379-391, (2001).

37. Chao, A., Chazdon, R. L., Colwell, R. K. \& Shen, T. J. Abundance-based similarity indices and their estimation when there are unseen species in samples. Biometrics $\mathbf{6 2}$, 361-371, (2006).

38. Hirzel, A. H., Hausser, J., Chessel, D. \& Perrin, N. Ecological-Niche Factor Analysis: How to Compute Habitat-Suitability Maps without Absence Data? Ecology 83, 20272036, (2002). 
39. Devictor, V. et al. Defining and measuring ecological specialization. J. Appl. Ecol. 47, 15-25, (2010).

40. Legendre, P. et al. Partitioning beta diversity in a subtropical broad-leaved forest of China. Ecology 90, 663-674, (2009).

41. Kanagaraj, R., Wiegand, T., Comita, L. S. \& Huth, A. Tropical tree species assemblages in topographical habitats change in time and with life stage. J. Ecol. 99, 1441-1452, (2011).

42. Punchi-Manage, R. et al. Effects of topography on structuring local species assemblages in a Sri Lankan mixed dipterocarp forest. J. Ecol. 101, 149-160, (2013).

43. Box, G. E. P. \& Cox, D. R. An Analysis of Transformations. J. R. Stat. Soc. B. 26, 211-252, (1964).

44. R Core Team. $R$ : A language and environment for statistical computing. , < https://www.R-project.org/> (2019).

45. Marcon, E. \& Hérault, B. entropart: An R package to measure and partition diversity. J. Stat. Softw. 67, 1-26, (2015).

46. Brenning, A. Statistical geocomputing combining R and SAGA: The example of landslide susceptibility analysis with generalized additive models. Hamburger Beiträge zur Physischen Geographie und Landschaftsökologie 19, 410, (2008).

47. Conrad, O. et al. System for Automated Geoscientific Analyses (SAGA) v. 2.1.4. Geoscientific Model Development 8, 1991-2007, (2015).

48. Calenge, C. The package "adehabitat" for the R software: A tool for the analysis of space and habitat use by animals. Ecol. Model. 197, 516-519, (2006). 

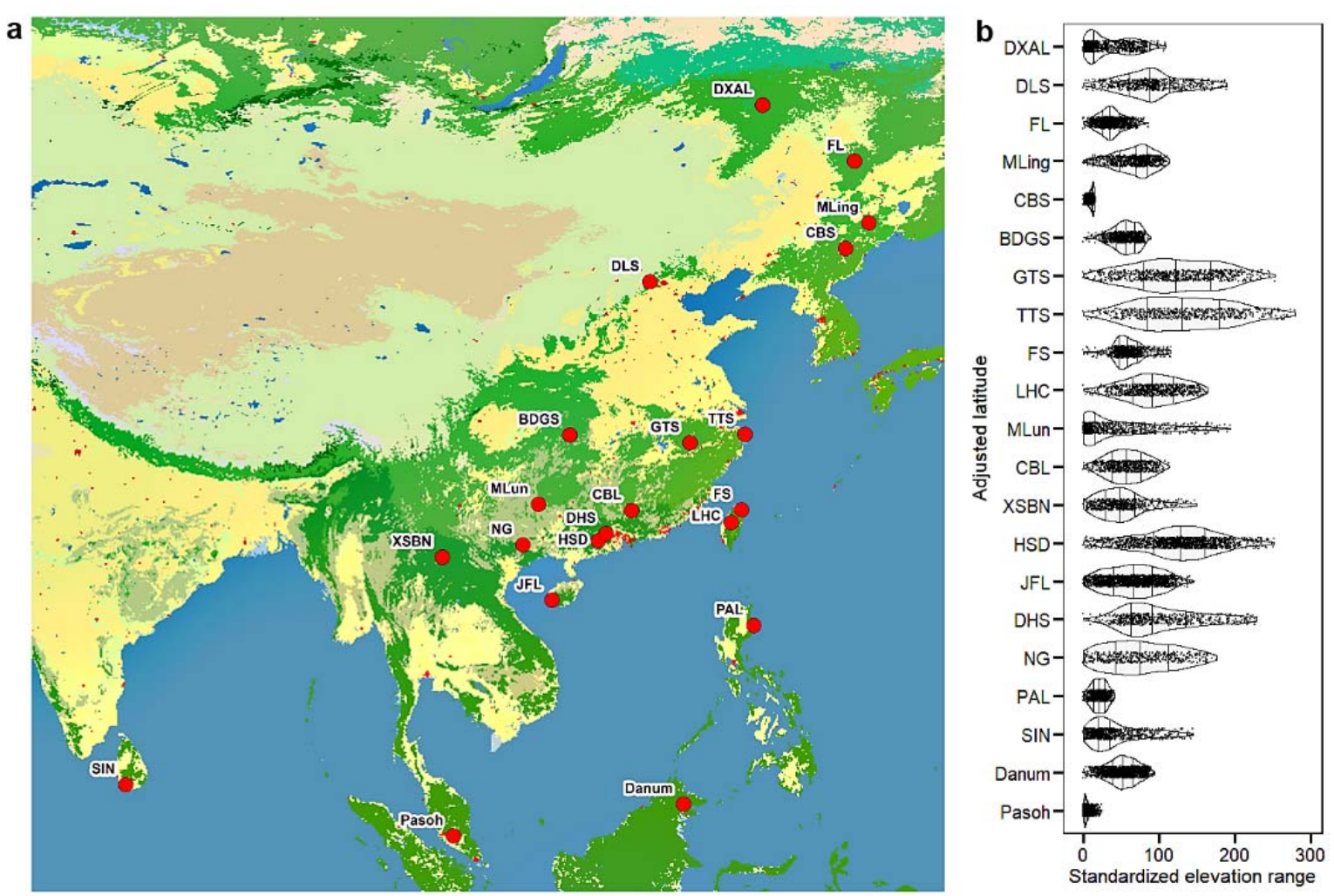

349 Figure 1 | The spatial distribution of forest dynamic plots (a, full plot names were listed

350 in Extended Data Table 1) and the elevation range of each plot along latitude (b). Panel b

351 shows the latitudinal pattern of elevation range, which was transformed by subtracting the

352 minimum elevation of each plot. Latitude was adjusted with mean elevation (an upward shift

353 of $100 \mathrm{~m}$ equal to a poleward shift of $100 \mathrm{~km}$ ). The width of each violin plot reflects

354 probability density distribution of mean elevation for $20 \mathrm{~m} \times 20 \mathrm{~m}$ subplots in each forest

355 dynamics plot. 

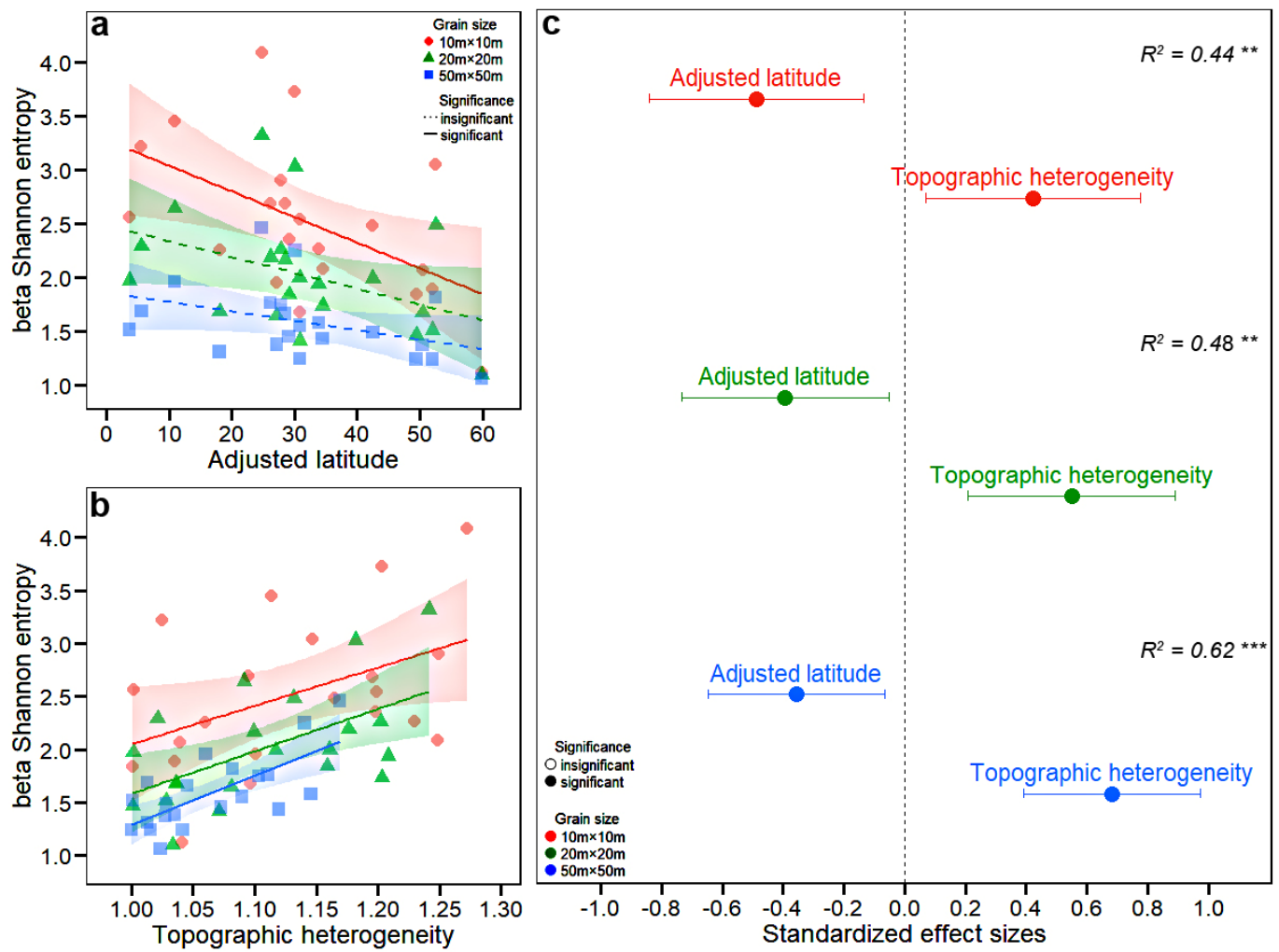

Figure 2 | The relationship of beta-diversity (corrected beta Shannon entropy) with adjusted latitude and local topographic heterogeneity across grain sizes. In each panel, different colours of points and lines represent grain sizes. In panel a and $b$, solid and dashed lines indicate significant and insignificant linear correlations (significance level, $\alpha=0.05$ ), respectively. The shaded areas represent the $95 \%$ confidence interval of the predictions. The results of these linear regression models for beta-diversity across scales in panel a and $\mathrm{b}$ were listed in Extended Data Table 2. In panel c, points represent the standardized effect sizes of explanatory variables, and solid circles represent the standardized effect sizes of variables being significantly different from zero. The significance level of the total $R$-square are $\alpha<$ 0.001, '***'; $\alpha<0.01$, ‘**’; $\alpha<0.05$ '*’. 

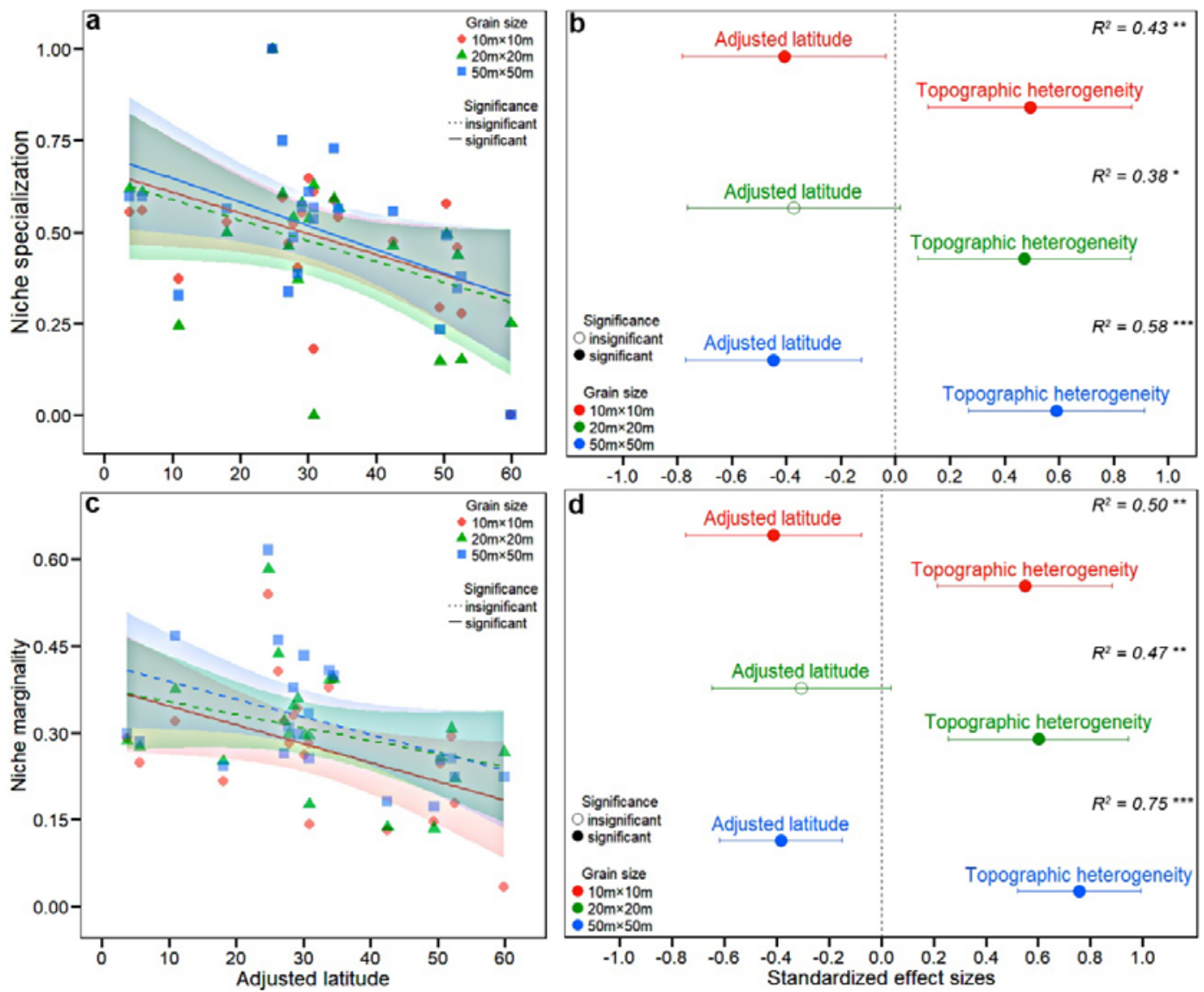

Figure 3 | The relationships of community-level niche specialization (a and b) and marginality (c and d) with adjusted latitude and local topographic heterogeneity across

grain sizes. In each panel, different colours of points and lines represent grain sizes. In panel a and c, solid and dashed lines indicate significant and insignificant linear correlations $(\alpha=$ 0.05), respectively. The shaded areas represent the $95 \%$ confidence interval of the predictions. The results of these linear regression models for niche specialization and marginality in panel $\mathrm{a}$ and $\mathrm{c}$ were listed in Extended Data Table 3. In panel $\mathrm{b}$ and d, points represent the standardized effect sizes of explanatory variables, and solid and hollow circles represent the standardized effect sizes of variables being significantly and insignificantly different from zero. The significance level of the total $R$-square are $\alpha<0.001$, '***'; $\alpha<0.01$, '**’; $\alpha<0.05$ '*'. 
Acknowledgements We thank Dingliang Xing, Tak Fung and Fangliang He for comments on

earlier draft. The data analyses reported in this study were financially supported by Strategic

Priority Research Program of the Chinese Academy of Sciences (XDB310300) and National

Natural Science Foundation of China (NSFC 31770478). Data collection was funded by many organizations, principally, NSFC 31470490, 31470487, 41475123, 31570426, 31570432, 31570486, 31622014, 31660130, 31670441, 31670628, 31700356, 31760141, and 31870404,

the Southeast Asia Rain Forest Research Programme (SEARRP), National Key Basic

Research Program of China (Grant No. 2014CB954100), SEARRP partners especially

Yayasan Sabah, HSBC Malaysia, financial project of Heilongjiang Provience

(XKLY2018ZR01), National Key R\&D Program of China (2016YFC1201102 and 2016YFC0502405), the Central Public-interest Scientific Institution Basal Research Fund (CAFYBB2017ZE001), Taiwan Forestry Research Institute grant under the project 97 AS-

7.1.1.F1-G1 and the Forestry Bureau of Taiwan (No. tfbm960226), CTFS Forest GEO for funding for Sinharaja forest plot, the Taiwan Forestry Bureau, the Taiwan Forestry Research Institute and the Ministry of Science and Technology of Taiwan for funding the census of plot, and we are grateful to Mike Bernados and Bill McDonald for species identifications, to

Fangliang He, Stuart Davies and Shameema Esufali for advice and training, to Qianjiangyuan

National Park, Fushan Research Center and Sri Lankan Forest Department for logistical support and the hundreds of field-workers who measured and mapped the trees analyzed in this study.

\section{Author contributions}

$\mathrm{KC}, \mathrm{RC}, \mathrm{XM}, \mathrm{KM}$ and JCS designed research, $\mathrm{KC}$ and XM compiled and analysed data; $\mathrm{KC}$, 
bioRxiv preprint doi: https://doi.org/10.1101/2020.07.14.200006; this version posted July 15, 2020. The copyright holder for this preprint (which

was not certified by peer review) is the author/funder, who has granted bioRxiv a license to display the preprint in perpetuity. It is made available under aCC-BY-NC-ND 4.0 International license.

408 Many authors contributed to data collection of forest censuses and all authors contributed to

409 revisions of the manuscript.

410

411 Competing interest

412 The authors declare no competing financial interests.

413

414

415 
bioRxiv preprint doi: https://doi.org/10.1101/2020.07.14.200006; this version posted July 15,2020 . The copyright holder for this preprint (which

was not certified by peer review) is the author/funder, who has granted bioRxiv a license to display the preprint in perpetuity. It is made available under aCC-BY-NC-ND 4.0 International license.

\section{$416 \quad$ Extended data}

417

418

Extended Data Table 1. | Basic information of 21 forest dynamic plots.

\begin{tabular}{|c|c|c|c|c|c|c|c|}
\hline Plot name & $\begin{array}{c}\text { Area } \\
\text { (ha) }\end{array}$ & $\begin{array}{l}\text { Latitude } \\
\left({ }^{\circ} \mathrm{N}\right)\end{array}$ & $\begin{array}{l}\text { Longitude } \\
\left({ }^{\circ} \mathrm{E}\right)\end{array}$ & $\begin{array}{c}\text { Mean } \\
\text { elevation } \\
(\mathrm{m})\end{array}$ & $\begin{array}{l}\text { Elevation } \\
\text { range }(\mathrm{m})\end{array}$ & $\begin{array}{l}\text { Gamma- } \\
\text { diversity }\end{array}$ & $\begin{array}{c}\text { Number } \\
\text { of } \\
\text { stems }\end{array}$ \\
\hline Pasoh & 50 & 2.98 & 102.31 & 80 & 24 & 818 & 335400 \\
\hline Danum Valley & 50 & 5.1 & 117.69 & 54.1 & 101.12 & 642 & 234916 \\
\hline Sinharaja & 25 & 6.4 & 80.4 & 499.5 & 151 & 239 & 250131 \\
\hline Palanan & 16 & 17.04 & 122.38 & 111 & 55 & 415 & 66000 \\
\hline Jianfengling & 60 & 18.73 & 108.9 & 932 & 150.4 & 290 & 439676 \\
\hline Xishuangbanna & 20 & 21.6 & 101.57 & 765.1 & 159.87 & 467 & 95834 \\
\hline Nonggang & 15 & 22.42 & 106.95 & 260 & 190 & 223 & 67870 \\
\hline Heishiding & 50 & 22.7 & 111.99 & 568.8 & 263 & 236 & 264391 \\
\hline Dinghushan & 20 & 23.17 & 112.52 & 339 & 240 & 195 & 71617 \\
\hline Lienhuachih & 25 & 23.91 & 120.88 & 765.4 & 178 & 144 & 153268 \\
\hline Chebaling & 20 & 24.72 & 114.22 & 488 & 131 & 222 & 86517 \\
\hline Fushan & 25 & 24.76 & 121.56 & 675.3 & 133 & 110 & 114500 \\
\hline Mulun & 25 & 25.13 & 108 & 547 & 208.8 & 254 & 144679 \\
\hline Gutianshan & 24 & 29.25 & 118.12 & 580.6 & 268.6 & 159 & 140700 \\
\hline Badagongshan & 25 & 29.77 & 110.09 & 1414 & 101 & 241 & 186556 \\
\hline Tiantongshan & 20 & 29.81 & 121.79 & 447.25 & 298.63 & 152 & 115536 \\
\hline Donglingshan & 20 & 40 & 115.43 & 1395 & 219.3 & 53 & 52136 \\
\hline Changbaishan & 25 & 42.22 & 128.53 & 801.5 & 17.7 & 52 & 38902 \\
\hline Muling & 25 & 43.95 & 130.07 & 719.5 & 123 & 57 & 63877 \\
\hline Fenglin & 30 & 48.08 & 129.12 & 439 & 66 & 46 & 94920 \\
\hline Daxinganling & 25 & 51.82 & 122.98 & 896.7 & 115.3 & 18 & 126532 \\
\hline
\end{tabular}

419 
bioRxiv preprint doi: https://doi.org/10.1101/2020.07.14.200006; this version posted July 15, 2020. The copyright holder for this preprint (which was not certified by peer review) is the author/funder, who has granted bioRxiv a license to display the preprint in perpetuity. It is made available under aCC-BY-NC-ND 4.0 International license.

420

Extended Data Table 2. | The results of simple linear regression models for beta-diversity across scales in Figure $2 \mathrm{a}$ and $\mathbf{2 b}$.

\begin{tabular}{lcccccc}
\hline $\begin{array}{l}\text { Explanatory } \\
\text { variables }\end{array}$ & Grain size & Coefficients & $\begin{array}{c}\text { Standard } \\
\text { error }\end{array}$ & t-value & p-value & R-square \\
\hline \multirow{3}{*}{ Adjusted } & $10 \mathrm{~m} \times 10 \mathrm{~m}$ & -0.024 & 0.01 & -2.59 & 0.02 & 0.26 \\
latitude & $20 \mathrm{~m} \times 20 \mathrm{~m}$ & -0.015 & 0.01 & -2.01 & 0.06 & 0.18 \\
& $50 \mathrm{~m} \times 50 \mathrm{~m}$ & -0.0087 & 0.01 & -1.86 & 0.08 & 0.15 \\
Topographic & $10 \mathrm{~m} \times 10 \mathrm{~m}$ & 3.62 & 1.65 & 2.19 & 0.04 & 0.20 \\
heterogeneity & $50 \mathrm{~m} \times 20 \mathrm{~m}$ & 4.00 & 1.33 & 3.02 & 0.007 & 0.32 \\
& & 4.63 & 1.08 & 4.28 & $<0.001$ & 0.49 \\
\hline
\end{tabular}

421

422 
bioRxiv preprint doi: https://doi.org/10.1101/2020.07.14.200006; this version posted July 15, 2020. The copyright holder for this preprint (which was not certified by peer review) is the author/funder, who has granted bioRxiv a license to display the preprint in perpetuity. It is made available under aCC-BY-NC-ND 4.0 International license.

Extended Data Table 3. The results of simple regression models for niche specialization and marginality against adjusted latitude in

\section{Figure $3 \mathrm{a}$ and $3 \mathrm{c}$.}

\begin{tabular}{lllllll}
\hline $\begin{array}{l}\text { Response } \\
\text { variables }\end{array}$ & Grain size & Coefficients & $\begin{array}{l}\text { Standard } \\
\text { error }\end{array}$ & t-value & $p$-value & R-square \\
\hline \multirow{2}{*}{ Niche } & $10 \mathrm{~m} \times 10 \mathrm{~m}$ & -0.0057 & 0.0027 & -2.10 & 0.049 & 0.19 \\
specialization & $20 \mathrm{~m} \times 20 \mathrm{~m}$ & -0.0056 & 0.0030 & -1.88 & 0.076 & 0.16 \\
& $50 \mathrm{~m} \times 50 \mathrm{~m}$ & -0.0065 & 0.0027 & -2.38 & 0.028 & 0.23 \\
Niche & $10 \mathrm{~m} \times 10 \mathrm{~m}$ & -0.0033 & 0.0015 & -2.15 & 0.044 & 0.20 \\
marginality & $20 \mathrm{~m} \times 20 \mathrm{~m}$ & -0.0022 & 0.0014 & -1.55 & 0.14 & 0.11 \\
\hline
\end{tabular}

425 
bioRxiv preprint doi: https://doi.org/10.1101/2020.07.14.200006; this version posted July 15, 2020. The copyright holder for this preprint (which was not certified by peer review) is the author/funder, who has granted bioRxiv a license to display the preprint in perpetuity. It is made available under aCC-BY-NC-ND 4.0 International license.

427

428

Extended Data Table 4. | The results of the simple regression models for beta-diversity measured by the Jaccard-Chao index in Extended Data Figure 1a and 1b.

\begin{tabular}{lllllll}
\hline $\begin{array}{l}\text { Explanatory } \\
\text { variables }\end{array}$ & Grain size & Coefficients & $\begin{array}{l}\text { Standard } \\
\text { error }\end{array}$ & t-value & $\mathrm{p}$-value & R-square \\
\hline \multirow{3}{*}{ Adjusted } & $10 \mathrm{~m} \times 10 \mathrm{~m}$ & -0.0025 & 0.001 & -3.03 & 0.0068 & 0.33 \\
latitude & $20 \mathrm{~m} \times 20 \mathrm{~m}$ & -0.0018 & 0.001 & -2.49 & 0.022 & 0.25 \\
& $50 \mathrm{~m} \times 50 \mathrm{~m}$ & -0.00068 & 0.0003 & -1.86 & 0.078 & 0.15 \\
Topographic & $10 \mathrm{~m} \times 10 \mathrm{~m}$ & 0.24 & 0.16 & 1.45 & 0.16 & 0.10 \\
heterogeneity & $50 \mathrm{~m} \times 50 \mathrm{~m}$ & 0.30 & 0.15 & 1.95 & 0.066 & 0.17 \\
\hline
\end{tabular}

430

431 
bioRxiv preprint doi: https://doi.org/10.1101/2020.07.14.200006; this version posted July 15,2020 . The copyright holder for this preprint (which was not certified by peer review) is the author/funder, who has granted bioRxiv a license to display the preprint in perpetuity. It is made available under ACC-BY-NC-ND 4.0 International license.

432

433

434

435

436

437

438

439

440

441

442

443
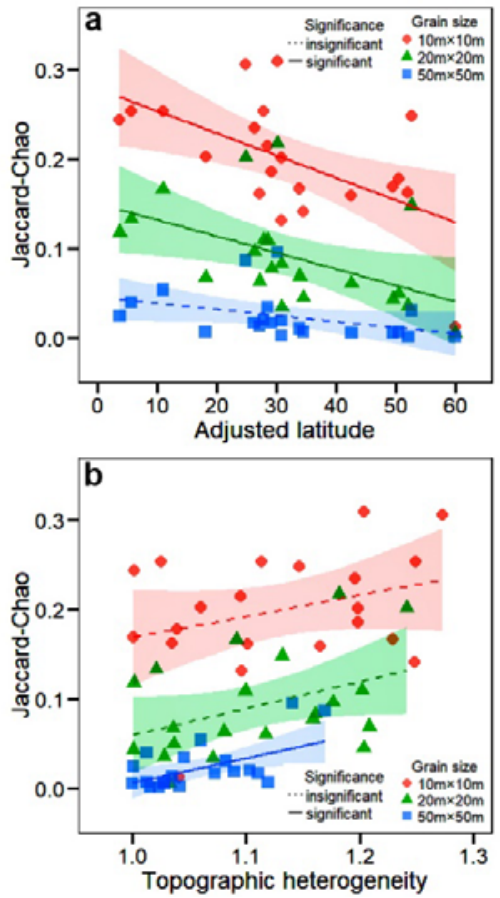

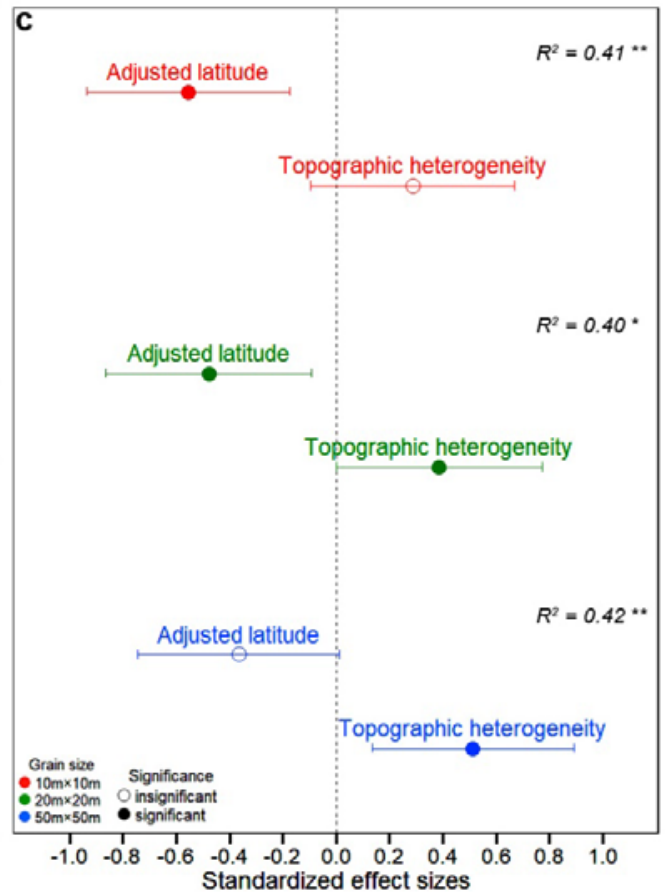

Extended Data Figure 1 | The linear relationship of beta-diversity (measured by the Jaccard-Chao index) with adjusted latitude (a) and local topographic heterogeneity (b) across grain sizes. In each panel, different colours of points and lines represent grain sizes. In panel a and b, solid and dashed lines indicate significant and insignificant linear correlations (significance level, $\alpha=0.05$ ), respectively. The shaded areas represent the $95 \%$ confidence interval of the predictions. In panel c, points represent the standardized effect sizes of explanatory variables, and solid and hollow circles represent variables with values significantly and insignificantly different from zero, respectively. The output of these linear

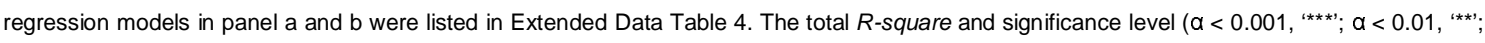
$\left.a<0.05^{(* \prime}\right)$ were annotated at the top-right corner for each multiple linear model in panel c. 
bioRxiv preprint doi: https://doi.org/10.1101/2020.07.14.200006; this version posted July 15,2020 . The copyright holder for this preprint (which was not certified by peer review) is the author/funder, who has granted bioRxiv a license to display the preprint in perpetuity. It is made available under aCC-BY-NC-ND 4.0 International license.
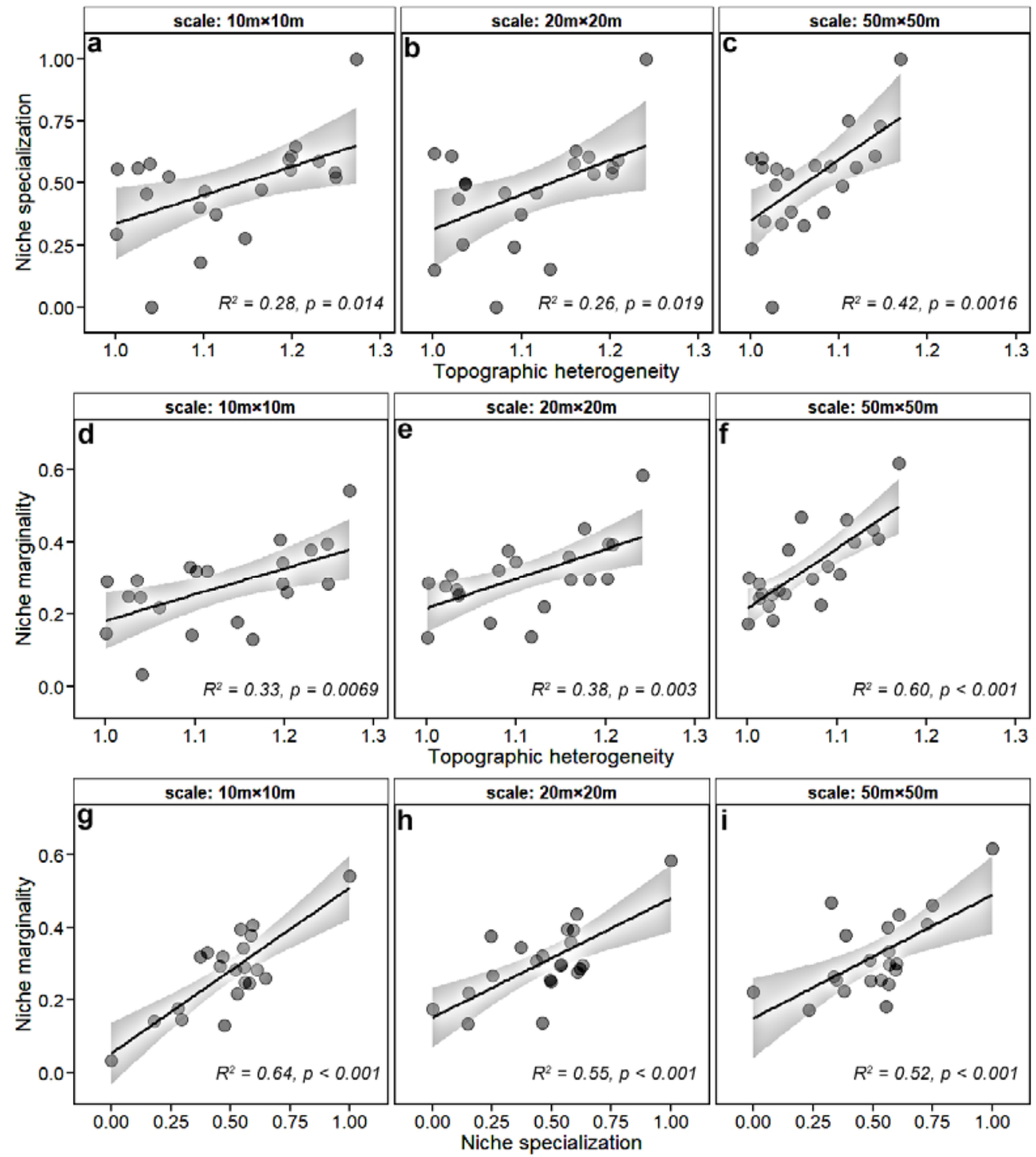

Extended Data Figure 2 | The linear relationships between topographic heterogeneity, community-level niche specialization and niche marginality across grain sizes (a, d and g: $10 \mathrm{~m} \times 10 \mathrm{~m}$; b, e and h: $20 \mathrm{~m} \times 20 \mathrm{~m} ; \mathrm{c}, \mathrm{f}$ and i: $50 \mathrm{~m} \times 50 \mathrm{~m})$. The niche specialization was transformed into normality using a Box-Cox transformation, and then was rescaled to the range in $[0,1]$ with the min-max normalization. Topographic heterogeneity was quantified as surface: Planimetric area ratio. The $R$-square and $p$-value were shown in each panel for simple linear regression models. 
bioRxiv preprint doi: https://doi.org/10.1101/2020.07.14.200006; this version posted July 15,2020 . The copyright holder for this preprint (which was not certified by peer review) is the author/funder, who has granted bioRxiv a license to display the preprint in perpetuity. It is made available under aCC-BY-NC-ND 4.0 International license.

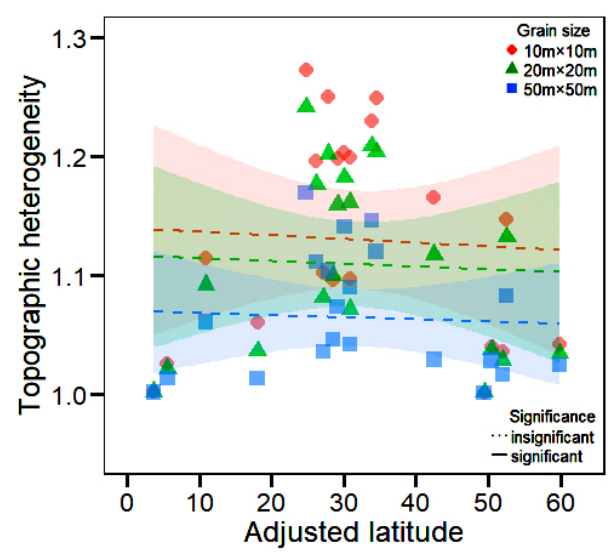

464

Extended Data Figure 3 | The linear relationship between topographic heterogeneity (quantified by the surface to planimetric area ratio) 
bioRxiv preprint doi: https://doi.org/10.1101/2020.07.14.200006; this version posted July 15, 2020. The copyright holder for this preprint (which was not certified by peer review) is the author/funder, who has granted bioRxiv a license to display the preprint in perpetuity. It is made available under aCC-BY-NC-ND 4.0 International license.

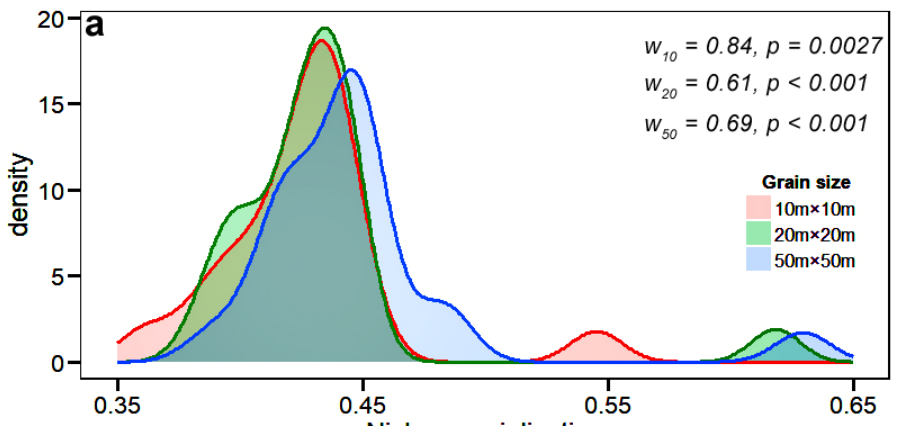

Niche specialization
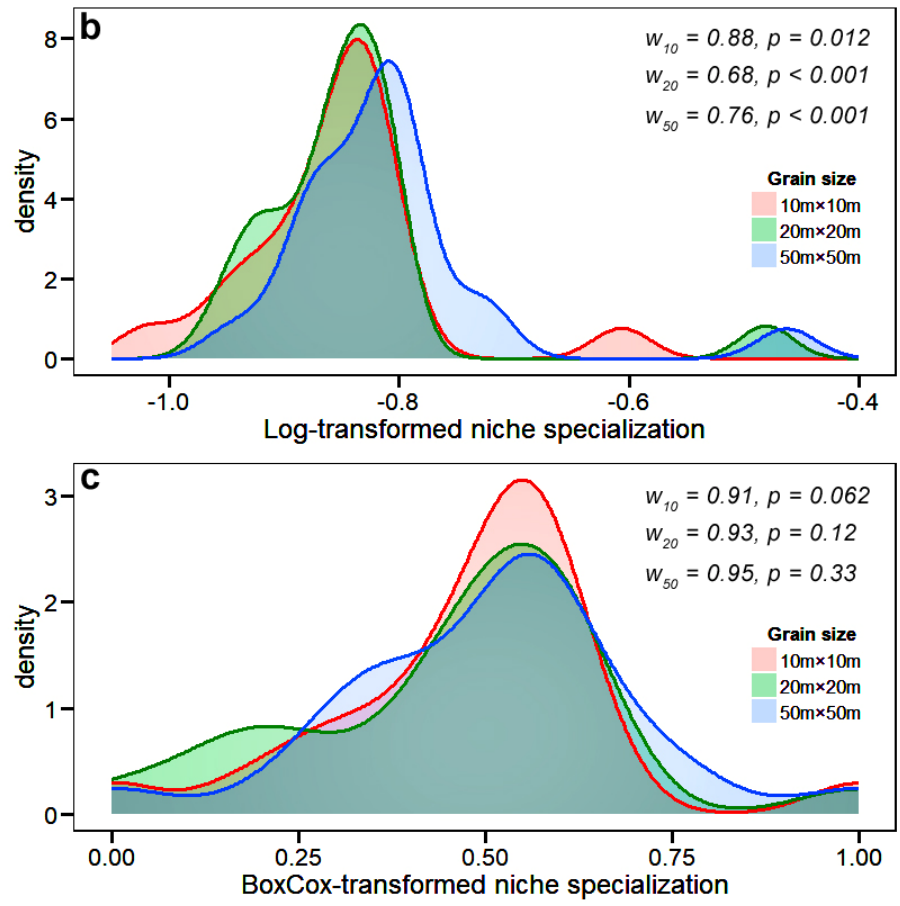